\title{
Second IAU Mid-Term Conference of Heads of Member Institutions Rio de Janeiro, 1-5 August 1988
}

At the kind invitation of the Council of Rectors of the Brazilian Universities, the International Association of Universities is to hold its Second Conference of Heads of Member Institutions in Rio de Janeiro from 1 to 5 August 1988. The theme will be: International University Co-operation, A Critical Analysis: Failures, Successes, Perspectives.A large number of university Presidents, Rectors and Vice-Chancellors from all parts of the world and representatives of major international and national university bodies are expected to take part in the Conference, which will provide a setting in which to come to grips with an issue of crucial significance for higher education leaders. At the same time, the meeting will serve as a unique occasion to establish or renew contacts with a view to strengthening co-operative ties.

When university officials are asked about their institution's involvement in international university co-operation, many can produce an impressive list of partners in various countries with whom they have some form of exchange. It would seem, therefore, that most university leaders agree not only on the desirability but the necessity of international co-operation and that benefits accrue to the teachers, researchers and students of their own institutions as a result of it.

Yet the empirical knowledge of the state of international university co-operation is rather meagre and discussions on the topic often appear to be based on overly idealistic assumptions. While there is general agreement that international co-operation is essential for the very functioning of higher education, the implementation of many exchange agreements encounter serious problems, and some accords exist only on paper. Such problems arise from different approaches, cultural, political and economic disparities, conflicting objectives, imperfect models or faulty strategies.

In much of this the issue of leadership is certainly crucial. It is fair to say that effective co-operation is enhanced when the head of a university is fully informed and aware of its importance, possibilities for mutual benefit and main outlines. Most heads also realize that true international co-operation goes beyond bilateral agreements with individual institutions. Such co-operation can indeed by greatly enhanced and strengthened by drawing on the benefits provided by multilateral structures and co-operative networks. Universities need, therefore, also to take an active part in the work of international university bodies.

The 1985 IAU General Conference in Los Angeles heard many calls for a systematic analysis of the problems of bilateral and multilateral international university co-operation. The Mid-Term Conference is an attempt to address this issue in a critical and conrrete way.

A social programme organized by the Brazilian hosts will complement the ideal Conference setting and provide opportunities to enjoy Brazilian culture and establish or renew contacts among the participants. 